\title{
T-2 MYCOTOXIN INDUCED APOPTOSIS IN BROILER'S LIVER TISSUE
}

\author{
Piret HUSSAR ${ }^{1}$, TÕNU JÄRVEOTS ${ }^{2}$, LAZO PENDOVSKI ${ }^{3}$, \\ KATERINA BLAGOEVSKA ${ }^{3}$, TRPE RISTOSKI ${ }^{3}$, \\ FLORINA POPOVSKA-PERCINIC ${ }^{3}$ \\ ${ }^{1}$ Faculty of Medicine, University of Tartu, Tartu, Estonia \\ ${ }^{2}$ Institute of Veterinary Medicine and Animal Sciences, \\ Estonian University of Life Sciences, Tartu, Estonia \\ ${ }^{3}$ Faculty of Veterinary Medicine, Ss. Cyril \& Methodius University in Skopje, \\ Republic of Macedonia
}

\begin{abstract}
Apoptosis is a process of programmed cell death that occurs in multicellular organisms. As T-2 toxin is known to induce apoptosis in mammalian cells, the aim of the present experiment was to study the toxic effect of T-2 on chicken liver tissue using apoptosis-related antibodies p21 and p53 which are involved in the $\mathrm{p} 53 / \mathrm{p} 21$-mediated apoptotic signalling pathway.

The experiment was conducted on fourteen 40-day-old broilers (Gallus gallus domesticus) who were divided into control and T-2 toxin groups. For the T-2 toxin group, T-2 toxin (Sigma, Germany) was dissolved in water and given per os for three consecutive days. The material of the liver was taken 24 hours after the last application. The specimens were fixed with $10 \%$ formalin and embedded into paraffin; slices $5 \mu \mathrm{m}$ in thickness were cut followed by immunohistochemical staining with polyclonal primary antibodies p21 and p53 (Abcam, UK) according to the manufacturer's guidelines (IHC kit, Abcam, UK).

Strong expression of p21 and p53 found in hepatocytes, endotheliocytes and around blood vessels together with large tissue destructions in T-2 toxin group birds' liver indicates apoptosis and histopathological changes in liver tissue during T-2 mycotoxicosis.
\end{abstract}

Keywords: T-2 mycotoxin; apoptosis; broilers; liver 


\section{INTRODUCTION}

According to literature, mycotoxins produced by Fusarium Spp. fungus can induce apoptosis - a programmed cell death - of several cell lines of humans and animals [22]. Since T-2 toxin is a main type A trichothecene mycotoxin which is the most toxic trichothecence, it has posed various toxic effects on humans and animals in vigorous cell proliferation tissues like lymphoid, hematopoietic and gastrointestinal tissues $[9,21]$. Simultaneously, T-2 toxin is one of the most important trichothecene mycotoxins which occurs in various agricultural products [20] causing severe diseases among humans and animals, which can even lead to death [12]. Since T-2 toxin causes acute and chronic toxicity and induces apoptosis in the immune system and fetal tissues [14], enormous number of fungal diseases have recently caused some of the most severe die-offs ever witnessed in wild species and are jeopardizing food security [5]. However, up to now the developmental toxicity of T-2 toxin and the exact mechanism of action at early life stages are not understood precisely.

Research on apoptosis has increased substantially since the early 1990s. Excessive apoptosis causes atrophy, whereas an insufficient amount results in uncontrolled cell proliferation, such as cancer.

Apoptosis is controlled by various pathways, some factors promote apoptosis, while some members of the Bcl-2 family of proteins inhibit apoptosis. One of the most important p53 functions is its ability to activate apoptosis [6], while p21 represents a major target of p53 activity and thus is associated with linking DNA damage to cell cycle arrest $[3,1,17]$.

T-2 toxin is known to induce apoptosis in mammalian cells; at the same time, there are relatively few notes about the topic on bird species $[4,19]$. Therefore, the aim of the investigation was to study the toxic effect of T-2 on chicken liver tissue using the antibodies p21 and p53 involved in apoptosis.

\section{MATERIAL AND METHODS}

In the experiment, fourteen 40-day-old ROSS broilers (Gallus gallus domesticus) were divided equally into control and T-2 toxin groups. For the whole duration of the experiment, broilers' requirements were met in accordance to the hybrid manufacturer; feed and water were given ad libitum, with a day:night regime of $23 \mathrm{~h}: 1 \mathrm{~h}$. For the T-2 toxin group, T-2 mycotoxin (Sigma, Germany; Cat. No. T4887) was dissolved in water and given per os $(0.250 \mathrm{mg} / \mathrm{chick} /$ day $)$ for three consecutive days, starting from the fifth day after hatching. On the 8th day of the experiment, chickens were sacrificed after total ether anaesthesia. 24 hours after the application of the last dose of toxin, the liver specimens, 
$0.5-1.0 \mathrm{~cm}$ in diameter, were fixed in $10 \%$ neutral buffered formalin solution, dehydrated in a series of alcohol, embedded into paraffin, and slices $5 \mu \mathrm{m}$ in thickness were cut (microtome Leica 2135). Thereafter, the slices were deparaffinized with xylene and rehydrated in a graded series of ethanol followed by staining with haematoxylin and eosin method (H\&E) [2] for the purpose of overall histological assessment and immunohistochemistry.

Immunohistochemical staining with polyclonal primary antibodies $\mathrm{p} 21$ and p53 (Abcam, UK) was carried out according to the manufacturer's guidelines (IHC kit, Abcam, UK). After the endogenous peroxidase activity was blocked with $3 \% \mathrm{H} 2 \mathrm{O} 2$, the sections were pre-treated using heat mediated antigen retrieval with sodium citrate buffer $(\mathrm{pH}$ 6) for $20 \mathrm{~min}$ and thereafter incubated with primary antibodies in $1 / 1000$ dilution for $30 \mathrm{~min}$ at $37^{\circ} \mathrm{C}$. Biotinylated secondary antibody and streptavidin-conjugated peroxidase which were contained in the IHC kit were used for detection using DAB as chromogen. Nuclei were counterstained with Harris Hematoxylin. Negative controls contained antibody diluent (Dako, S0809) instead of primary antibodies.

The experimental protocol was approved by the Ethical Committee of Ss. Cyril \& Methodius University in Skopje in conformity with the recommendation provided in the European Convention for the Protection of Vertebrate Animals used for Experimental and Other Scientific Purposes (ETS no. 123, Appendix A) (No. 03-7534 from 12.04.2013).

\section{RESULTS}

In the experimental group, areas with large tissue destructions were noticed (Fig.1a) compared to the control group broilers with normal liver lobular histology (Fig.1b).
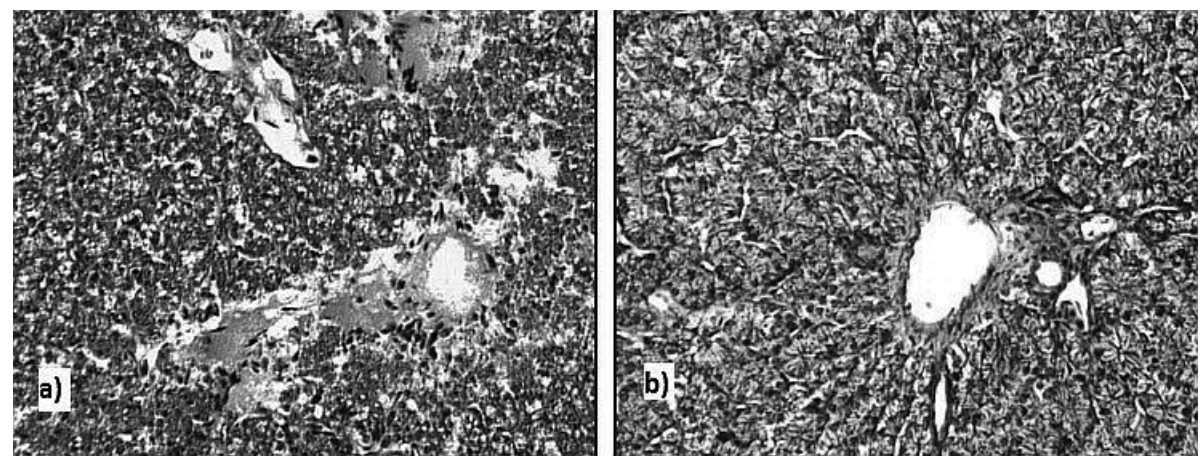

Figure 1. a) Areas with destruction of the liver lobular histology after T-2 administration. H\&E; $\times 200$; b) Normal liver tissue structure in control broilers. H\&E; $\times 200$. 
In the T-2 toxin group, mononuclear cell infiltration was found in the liver Kiernani's interlobular spaces (Figure 2a). In T-2 group broilers, fat degeneration of hepatocytes was noticed in the form of small lipid vacuoles present in their cytoplasm (Figure 2b). Fat degeneration was observed in the central parts of the lobules around vena centralis as well as in the ventral and periportal parts of the liver lobules.
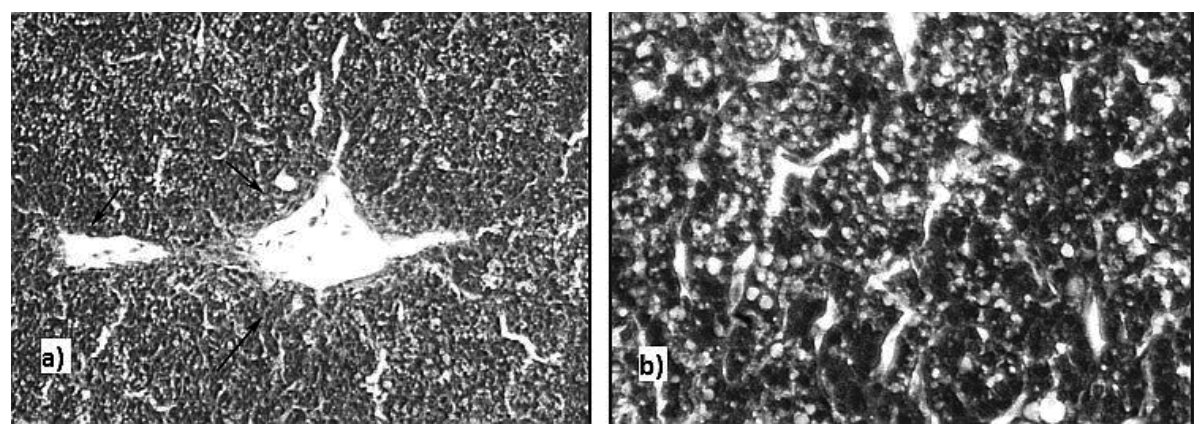

Figure 2. a) Mononuclear cell infiltration in the connective tissue of Kiernani's interlobular spaces (arrows) after T-2 administration H\&E; $\times 200 ;$ b) Small lipid vacuoles present in hepatocyte's cytoplasm indicating fat degeneration. $\mathrm{H} \& \mathrm{E} ; \times 400$.

Strong expression of p21 was noted in the nuclei of hepatocytes and sinusoidal endothelial cells (Fig. 3a) in the liver tissue of the T-2 toxin group compared to the control group (Fig. 3b). The analyses of the T-2 group birds' liver tissue showed areas with large destructions of the normal liver lobular histology.
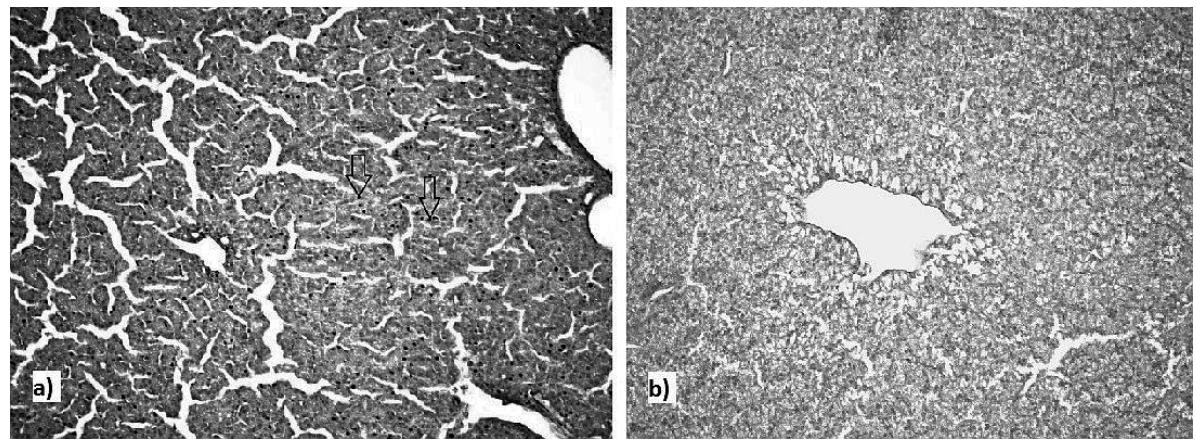

Figure 3. a) Strong expression of p21 in hepatocytes nuclei (arrows) in T-2 mycotoxicated chicken. Note also the destructed liver tissue. $\times 200$. b) Control group without T-2 intoxication. No specific expression of p21 is noted in chicken liver. $\times 200$. 
The expression of p53 was noted in hepatocytes, endotheliocytes and Kupffer cells, around lobular and interlobular blood vessels (Fig. 4ab). In both stains, cell shrinkage and nuclear condensation was noted in apoptotic cells. No tissue destructions or strong expression of the antibodies were noted in the liver tissue of the control group's chickens.
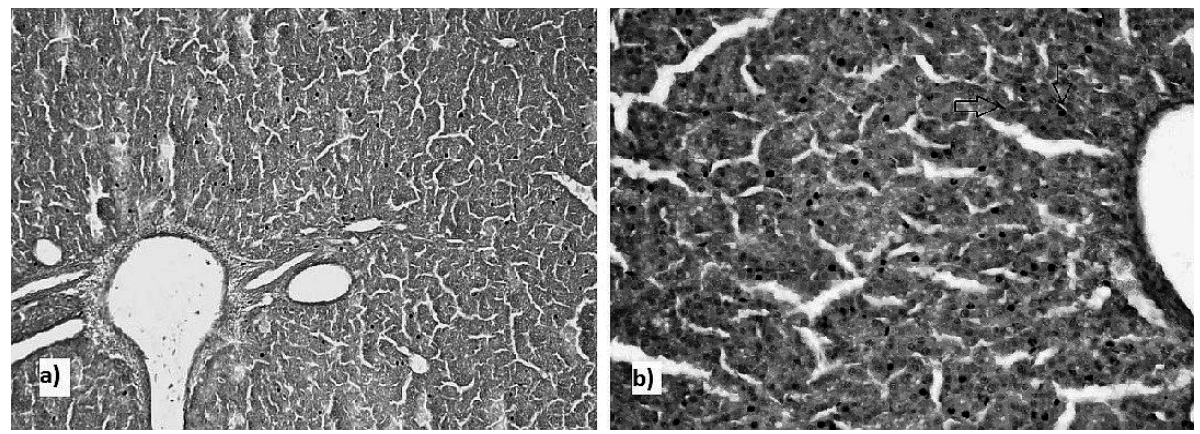

Figure 4. a) Destructured chicken liver tissue after T-2 mycotoxin administration. IHC for p53 - strong expression in nuclei of hepatocytes and in endotheliocytes. $\times 200$; b) Strong expression of p53 in nuclei of hepatocytes and Kupffer cells (arrows) as well as in perivascular areas in T-2 mycotoxicated chicken. $\times 400$.

\section{DISCUSSION AND CONCLUSION}

According to the literature sources, the influence of T-2 toxin on different tissues has been studied intensively in recent years. It has been found that T-2 toxin induces tissue apoptosis in vivo in mice thymus [11]. Histopathological examination of the thymus indicated that the pattern of cell death in the thymocytes had a characteristic apoptotic morphology with cell shrinkage and nuclear condensation. These findings suggest that T-2 toxin-induced thymic atrophy is associated with cell death through a mechanism of apoptosis.

In a study on the apoptosis mechanism in liver cells induced by $\mathrm{T}-2$ toxin [21], it was also found that p53 was up-regulated under T-2 toxin stress, which implied that the effect of T-2 toxin on cells was apoptosis rather than necrosis, and it was probably induced through the mitochondrial pathway. The induction of apoptosis of T-2 toxin through a possible mechanism involving reactive oxygen species-mediated mitochondrial pathway is also supported by other authors [13].

The effect of T-2 toxin is reported to be quick and also inducing apoptosis in embryonic tissues [10]. At 24 hours after T-2 toxin-inoculation, moderate 
pyknosis or karyorrhexis was generally observed in some layers of the central nervous system.

Our investigation of chickens' liver tissue in T-2 group revealed tissue destructions with fat degeneration of hepatocytes, mononuclear cell infiltration in the liver Kiernani's interlobular spaces, strong expression of p21 and p53 in hepatocytes, sinusoidal endotheliocytes and in perivascular areas indicating to histopathological changes and apoptosis in liver tissue during T-2 mycotoxicosis. Our findings of apoptosis after T-2 application are in accordance with data from Rocha et al. [15] who suggested that T-2 is a very strong inhibitor of protein and nucleic acid synthesis; inhibitors of mitochondrial function and cell division can induce cell apoptosis. Earlier studies on mice to whom $2.5 \mathrm{mg} / \mathrm{kg}$ of T-2 toxin was given showed that this toxin is a potent inducer of apoptotic cell death in liver, where Kupffer cells play a significant part for clearance of apoptosis [9].

As the main target of the toxic effects of T-2 toxin in vivo is liver, which plays an important role as first line defence mechanism by the process called the first-pass effect $[16,17]$, more studies in this field are required in future.

\section{REFERENCES}

1. Bunz F., Dutriaux A., Lengauer C., Waldman T., Zhou S., Brown J.P., Sedivy J.M., Kinzler K.W., Vogelstein B. (1998). Requirement for p53 and p21 to sustain G2 arrest after DNA damage. Science, 282 (5393), 1497-1501.

2. Carson F.L. (1997). Histotechnology. ASCP Press, Chicago, USA.

3. El-Deiry W.S., Tokino T., Velculescu V.E., Levy D.B., Parsons R., Trent J.M., Lin D., Mercer W.E., Kinzler K.W., Vogelstein B. (1993). WAF1, a potential mediator of p53 tumor suppression. Cell, 75 (4), 817-25.

4. Ge X.H., Wang, J.P., Liu, J., Jiang, J., Lin, H.N., Wu, J., Ouyang, M., Tang, X.Q., Zheng, M., Liao, M., Deng, Y.Q. (2010). The catalytic activity of cytochrome P450 3A22 is critical for the metabolism of T-2 toxin in porcine reservoirs. Catal Commun, 12, 71-75.

5. Fisher M.C., Henk, D.A., Briggs C.J., Brownstein J.S., Madoff L.C., McCraw S.L., Gurr S.J. (2012). Emerging fungal threats to animal, plant and ecosystem health. Nature, 484, 186-194.

6. Fridman J.S., Lowe S.W. (2003). Control of apoptosis by p53. Oncogene, 22, 9030-9040.

7. Gartel A.L., Tyner A.L. (2002). The role of the cyclin-dependent kinase inhibitor p21 in apoptosis. Mol Cancer Ther, 1(8), 639-49. 
8. Ihara T., Sugamata M., Sekijima M., Okumura H., Yoshino N., Ueno Y. (1997). Apoptotic cellular damage in mice after T-2 toxin-induced acute toxicosis. Nat Toxins, 5, 4, 141-145.

9. Kumagai S., Shimizu T. (1988). Effects of Fusarenon-X and T-2 toxin on intestinal absorption of monosaccharide in rats. Arch Toxicol, 61, 489-495.

10. Ishigami N., Shinozuka J., Katayama K., Uetsuka K., Nakayama H., Doi K. (1999). Apoptosis in the developing mouse embryos from T-2 toxin-inoculated dams. Histology and Histopathology, 14, 3.

11. Islam Z., Nagase M., Yoshizawa T., Yamauchi K., Sakato N. (1998). T-2 toxin induces thymic apoptosis in vivo in mice. Toxicol Appl Pharmacol., 48(2), 205-14.

12. Kachuei R., Rezaie S., Hossein Yadegari M., Safaie N., Allameh A.-A., ArefPoor M.-A., Imani Fooladi A.-A., Riazipour M., Mohammad Abadi H.M. (2014). Determination of T-2 Mycotoxin in Fusarium strains by HPLC with fluorescence detector. Journal of Applied Biotechnology Reports, 1, 1, 38-43.

13. Lei Y., Guanghui Z., Xi W., Yingting W., Xialu L., Fangfang Y., Goldring M.B., Xiong G., Lammi M.J. (2017). Cellular responses to T-2 toxin and/or deoxynivalenol that induce cartilage damage are not specific to chondrocytes. Scientific Reports, 7, 2231.

14. Li Y., Wang Z., Beier R.C., Shen J., De Smet D., De Saeger S., Zhang S. (2011). T-2 Toxin, a Trichothecene Mycotoxin: Review of Toxicity, Metabolism, and Analytical Methods. J Agric Food Chem, 59, 8, 3441-3453.

15. Rocha O., Ansari K., Doohan F.M. (2005). Effects of trichothecene mycotoxins on eukaryotic cells: a review. Food Addit Contam, 22, 369-378.

16. Osselaere A. (2013). Influence of deoxynivalenol and T-2 toxin on the intestinal barrier and liver function in broiler chickens. $\mathrm{PhD}$ dissertation, Ghent University.

17. Smith T.K. (1992). Recent Advances in the Understanding of Fusarium trichothecene mycotoxicoses. J Anim Sci, 70, 3989-3993.

18. Waldman T., Kenneth W., Vogelstein K., Vogelstein B. (1995). p21 is necessary for the p53-mediated G1 arrest in human cancer cells. Cancer research, 55, 22, 5187-5190.

19. Tompkins L.M., Wang H. (2011). Liver Drug Metabolism. In: Hu M., Li X. (Eds.). Oral Bioavailability - Basic Principles, Advanced Concepts, and Applications. John Wiley \& Sons, Hoboken, 127-144.

20. Yuan G., Wang Y., Yuan X., Zhang T., Zhao Y., Huang L., Peng S. (2014). T-2 toxin induces developmental toxicity and apoptosis in zebrafish embryos. Journal of Environmental Sciences, 26, 4, 917-925.

21. Zhang Y., Han Y., Zhu C.C., Tang F., Cui X.-S., Kim N., Sun S.-C. (2016). Exposure to HT-2 toxin causes oxidative stress induced apoptosis/autophagy in porcine oocytes. Scientific Reports, 6, 33904. 
22. Zhuang Z., Yang D., Huang Y., Wang S. (2013). Study on the Apoptosis Mechanism Induced by T-2. Toxin P LoS One, 8(12), e83105.

Address for correspondence:

Piret Hussar, M.D., D.M.Sc

Chair of Histology and Embryology, Department of Anatomy

Institute of Biomedicine and Translational Medicine, Faculty of Medicine

University of Tartu, Ravila 19, Tartu 50411, Estonia

E-mail: piret.hussar@ut.ee 